\title{
Lipid Management in the Elderly Population
}

\author{
Micheli Ito Gimenes Pires, Thaise de Araujo Wrubleski, and Gustavo Lenci Marques
}

\section{ABSTRACT}

\begin{abstract}
Considering that deaths from cardiovascular disease have been increasing in proportion to population ageing, prevention and treatment of dyslipidemia in elderly people is essential to avoid such outcome. Some biomarkers, albeit with limitations, have shown effectiveness in predicting cardiovascular events. Among them, blood levels of $\mathrm{C}$-reactive protein, Lipoprotein A and, especially, coronary artery calcium. Dyslipidemia management primarily includes changes in lifestyle, such as physical activity, diet and smoking cessation. However, in elderly, drug therapy may be necessary, with statins being the first line treatment. In addition, therapies with drugs that decrease intestinal cholesterol absorption or increase LDL absorption by the liver, for example, have shown benefit when added to conventional therapy. Therefore, this review aims to contemplate some aspects of dyslipidemia in the elderly population, since appropriate management of such condition can significantly avoid undesirable outcomes.
\end{abstract}

Keywords: cardiovascular disease, cholesterol, dyslipidemia, elderly, statins.

\section{INTRODUCTION}

About one million Americans die each year from cardiovascular disease (CVD). Coronary artery disease and stroke are the main clinical manifestations. CVD is considered the main cause of death in developing countries and its prevalence is increasing annually along with population aging [1].

Smoking, dyslipidemia, hypertension, diabetes, abdominal obesity, psychosocial factors, lack of daily consumption of fruits and vegetables, regular consumption of alcohol and lack of regular physical activity are the nine potentially modifiable factors responsible for more than 90 percent of the risk attributable to a first acute myocardial infarction [2]. Among the main risk factors, it is known that the levels of low-density lipoprotein (LDL-c) are directly related to the increase in atherosclerotic cardiovascular disease (ASCVD) [3].

The Cardiovascular Lifetime Risk Pooling Project study, in 2012, carried out a meta-analysis which included 18 studies and gathered data from more than 250 thousand participants. This study concluded that the presence of many risk factors at all ages resulted in markedly higher risk of cardiovascular disease throughout life [4].

As far as the prevention and treatment of CVD, consequently including the control of LDL-c levels, the first step continues to be lifestyle change, which includes regular diet, with reduced intake of cholesterol, saturated fat and transfatty acids, daily intake of fibers, stop smoking and the establishment of a physical activity routine with min 30 minutes/day of moderate intensity physical exercises.
Submitted : February 1, 2021

Published : February 24, 2021

ISSN: $2593-8339$

DOI: $10.24018 /$ ejmed.2021.3.1.697

\section{I. G. Pires}

Cajuru University Hospital, Curitiba, Paraná, Brazil.

(e-mail: micheliigp@ $@$ hotmail.com)

T. A. Wrubleski

Cajuru University Hospital, Curitiba, Paraná, Brazil.

(e-mail: thaise.aw29@gmail.com)

G. L. Marques*

Pontifical Catholic University of Paraná, Curitiba, Paraná, Brazil.

(e-mail: gustavolencimarques ${ }^{\circledR}$ gmail.com)

*Corresponding Author
However, adherence to these measures can be difficult for the elderly population, so the combination with drug therapy might bring better results, and statins are widely accepted as first-line drug therapy [5]-[7].

\section{STRATIFICATION}

\section{A. C-Reactive Protein and Lipoprotein(a)}

Some biomarkers have been implemented for predicting cardiovascular events. C Reactive Protein, an inflammatory marker, proved to be beneficial in predicting coronary risk as well as being associated with the risk of mortality. On the other hand, it is more reliable when other inflammatory markers are also present. Even if CRP has shown some benefit in predicting clinical events, mainly for early outcomes, caution is necessary as elderly people have naturally higher blood levels of this marker [8]. Another stratification marker, Lipoprotein (a) or LP(a), which is a subclass of lipoprotein like LDL, has shown association with cardiovascular risk, proportional to higher serum level of this component, even in elderly people and also after adjustment for risk factors and ethnic groups. In the context of pathophysiology, it could be explained as Lp(a) contributes to aortic stiffness, lipid rich unstable plaques and valve calcification [8], [9].

\section{B. Coronary Artery Calcium (CAC)}

It is well known in the literature that Coronary Artery Calcium (CAC) has been widely used for predicting events. A ten-year trial revealed CAC as an independent risk factor for atherosclerotic cardiovascular disease (ASCVD) events, 
including stroke. This association is true even when adjusted for age, sex or race. According to such study, when first event was accounted for analysis, those with $\mathrm{CAC}>=100$ had at least 7.5\% 10-year risk of cardiovascular event. Besides that, 10-year ASCVD risk depends on CAC categories, where $\mathrm{CAC}=0$ represents less than $6 \%$ and $\mathrm{CAC}>300$ represents more than $13 \% 10$-year risk. In the same way, there is $14 \%$ relative increased risk for each doubling of CAC [10]. Similarly, some authors reported that coronary heart disease was directly proportional to extent of CAC for both white women and men and also for black women. Comparing white women with $\mathrm{CAC}=0$ vs. $\mathrm{CAC}>400$, the incidence of myocardial infarction was 0 vs. $19 \%$, respectively. In the same way, among women, 0 or very low CAC value was also associated to lower incidence of dementia. However, it is reasonable to consider that few participants had $\mathrm{CAC}=0$ in this study [11].

\section{Statins}

Statins are considered first-line drugs for the treatment of dyslipidemia. The mechanism of action of this drug is based on the reduction of cholesterol synthesis through the partial and reversible reduction of the activity of the enzyme 3hydroxy-3-methylglutaryl (HMG) -CoA reductase [12].

In a large meta-analysis encompassing 14 randomized trials of statin drugs, during a mean of 5 years, it was seen a $12 \%$ reduction in all-cause mortality per $\mathrm{mmol} / \mathrm{L}$ of $\mathrm{LDL}$ cholesterol reduction. Consequently, there was important reduction in events like coronary mortality, myocardial infarction and the need for coronary revascularization, as well as stroke (fatal and non-fatal) and any such major vascular event, being all of them statistically significant $(p<0.001)$. Moreover, the benefits of the use of statins were greater in subsequent years, but also within the first year [13].

Despite the scarcity of studies that include elderly people over 75 years, a large prospective study, Pravastatin in elderly individuals at risk of vascular disease (PROSPER), aimed to analyze the lipid-lowering effect of pravastatin specifically in the elderly population. For 3.2 years 2,804 men and 3,000 women aged 70-82 years and history or risk factors for vascular disease were followed up in this randomized, double-blind, controlled study. The results revealed that pravastatin $40 \mathrm{mg} / \mathrm{d}$ reduced the concentration of LDL cholesterol in $34 \%$ of the patients in the case group and, consequently, mortality from coronary heart disease fell by $24 \%$ in this same group [12].

Additionally, Downs et. al. presented a 36\% risk reduction for first acute major coronary events in participants receiving Lovastatin, in relation to those receiving placebo. In this sample, $22 \%$ were older than 65 years, and the risk reduction were similar to the younger patients [14].

In the same way, other solidified studies, as The Heart Protection Study (HPS), showed that Simvastatin therapy reduced rates of stroke, myocardial infarction and revascularization, similarly and significant for those aged either over or under 70 years at entry. Furthermore, Sever et.al. and Neil et. al. concluded that Atorvastatin also has a benefit in preventing cardiovascular disease independently of participants age at entry [15]-[17].

Although statins are generally considered safe medications, patients with multiple associated comorbidities are more susceptible to adverse effects. The increase in liver enzymes and myopathy are the most worrying side effects, with the consequent rhabdomyolysis being a serious adverse effect that can develop in $0.1 \%$ of the population, mainly in patients with coexisting renal failure. Thus, even if statins use for secondary prevention of cardiovascular disease is well stablished in the literature, the primary prevention must be individualized, considering the clinical risk of each patient [18].

It is advisable to start statins progressively and avoid their concomitant use with other drugs, to reduce the rate of associated adverse effects [6]. The rate of discontinuation of medication in the elderly is less than $10 \%$ [19]. Despite the well-known safety involved in treatment with statins, other lipid-lowering agents may be needed in the treatment of dyslipidemia.

\section{ADDITIONAL DRUG THERAPIES}

\section{A. Ezetimibe}

Some alternative drugs have shown relevance additionally to conventional therapy with statins. Ezetimibe, a drug which reduces intestinal cholesterol absorption, when associated to Simvastatin seems to reduce an additional $24 \%$ approximately in LDL levels after 1 year. In a double blinded RCT, 18.144 participants who had been hospitalized for acute coronary syndrome within past 10 days, previously receiving or not lipid lowering therapy, were equally allocated to receive Simvastatin $40 \mathrm{mg}+$ Ezetimibe $10 \mathrm{mg}$ in the first group or Simvastatin $40 \mathrm{mg}+$ Placebo in the second group.

The primary outcome, defined as a composite of cardiovascular death, myocardial infarction, hospital admission for unstable angina, revascularization (> 30 days after randomization), or non-fatal stroke, after 7 years, was $32.7 \%$ in Simvastatin-Ezetimibe group and $34.7 \%$ in Simvastatin monotherapy group, granting statistically significant absolute risk reduction of 2.0 percentage points, and number needed to treat (NNT) corresponding to 50 for primary outcome and 58 for myocardial infarction, respectively [20].

Besides that, to improve that trial, Erin et. al. used TIMI Risk Score for Secondary Prevention to identify greatest population that would benefit from Ezetimibe added to Statin therapy. High risk patients presented $6.3 \%$ absolute risk reduction in 7 years with introduction of Ezetimibe, being $\mathrm{NNT}=16$, while intermediate risk patients had NNT $=45$ Low risk patients did not show real benefit by adding Ezetimibe to Statin [21]. Additionally, Richard et. al. reported that patients aged 75 years or older had even greater absolute risk reduction of primary end point, being the number needed to treat $=11$ [22].

\section{B. PCSK9-inhibitors}

PCSK9 inhibitors, represented by monoclonal antibodies that inactivate PCSK9, increasing LDL uptake by the liver, proved benefit in reducing LDL blood levels. An important study evaluating Evolocumab, a member of this class of drug, showed 59\% reduction in LDL cholesterol levels when it was associated to statin therapy (median baseline LDL $92 \mathrm{mgdL}$ to $30 \mathrm{mgdL}$ ) and $15 \%$ reduction in the risk of primary 
outcome (a composition of cardiovascular death, myocardial infarction, stroke, hospitalization for unstable angina, or coronary revascularization). Besides that, adverse effects, as neurocognitive impairment, did not increase with the use of Evolocumab, except for rare injection-site reactions [23]. Nevertheless, costs attributed to such medication exceed any savings achieved by preventing cardiovascular events, and for being cost-effective, PCSK9 inhibitors expenses should significantly be reduced [24].

\section{Fibrates}

Finally, Fibrates is another class of medication used as lipid lowering, mainly for hypertriglyceridemia and low HDLc. Some studies have shown its benefit in reducing cardiovascular disease, but with no impact on mortality. Most evidence did not include elderly patients, especially those older than 75 years, and some side effects have been reported with the use of Fibrates, such as Myopathy, mainly in association to statin. Therefore, real benefit in this population remains unclear [8].

\section{CONCLUSION}

Among elderly population, the use of statins and additional drug therapies has shown benefit in the management of dyslipidemia. This study aimed to compile evidence for the treatment of this population, as the number of people in this age group increases progressively. However, there are few studies involving specially those over 75 years old and further studies are needed to complement the current evidence.

\section{ACKNOWLEDGMENT}

Special thanks to Cajuru University Hospital (HUC) for the assistance and encouragement of scientific research, as well as serving as a field for improvement of the health service, contributing to the intellectual, professional and personal growth of its collaborators and users.

\section{REFERENCES}

[1] Benjamin EJ, Muntner P, Alonso A, Bittencourt MS, Callaway CW, Carson AP, et al. Heart Disease and Stroke Statistics-2019 Update: A Report from the American Heart Association. Vol. 139, Circulation. 2019. 56-528 p.

[2] Pa CK. The effective history of critical theory: The reception history of Frankfurt school in Taiwan Universitas (Stuttg). 2010;37(6):111-25.

[3] Ference BA, Ginsberg HN, Graham I, Ray KK, Packard CJ, Bruckert E, et al. Low-density lipoproteins cause atherosclerotic cardiovascular disease. 1. Evidence from genetic, epidemiologic, and clinical studies. A consensus statement from the European Atherosclerosis Society Consensus Panel. Eur Heart J. 2017;38(32):2459-72.

[4] Berry JD, Dyer A, Cai X, Garside DB, Ning H, Thomas A, et al. Lifetime Risks of Cardiovascular Disease. N Engl J Med. 2012;366(4):321-9.

[5] Pate RR, Pratt M, Blair SN, Haskell WL, Macera CA, Bouchard C, et al. Public Health and Prevention and the American College of Sports Medicine. J Am Med Assoc. 1995;273(5):402-7.

[6] Shao H, Chen LQ, Xu J. Treatment of dyslipidemia in the elderly. J Geriatr Cardiol. 2011;8(1):55-64.

[7] Adult Treatment Panel III (2002) Third report of the National Cholesterol Education Program (NCEP) Expert Panel on detection, evaluation, and treatment of high blood cholesterol in adults. Circulation 106: 31433421.

[8] Streja E, Streja DA. Management of Dyslipidemia in the Elderly [Internet]. Endotext [Internet]. 2020. Available from: https://www.ncbi.nlm.nih.gov/books/NBK279133/.
[9] Milionis HJ, Filippatos TD, Loukas T, Bairaktari ET, Tselepis AD, Elisaf MS. Serum lipoprotein(a) levels and apolipoprotein(a) isoform size and risk for first-ever acute ischaemic nonembolic stroke in elderly individuals. Atherosclerosis. 2006;187(1):170-6.

[10] Budoff MJ, Young R, Burke G, Carr JJ, Detrano RC, Folsom AR, et al. Ten-year association of coronary artery calcium with atherosclerotic cardiovascular disease (ASCVD) events: the multi-ethnic study of atherosclerosis (MESA). Eur Heart J. 2018;39(25):2401b-2408b.

[11] Lewis H. Kuller, Lopez OL, Macke RH, Rosano C, Edmundowicz D, Becker JT, et al. Subclinical Cardiovascular Disease and Death, Dementia, and Coronary Heart Disease in Individuals Age 80+. Physiol Behav. 2018;176(1):139-48.

[12] Shepherd J, Blauw GJ, Murphy MB, Bollen ELEM, Buckley BM, Cobbe SM, et al. Pravastatin in elderly individuals at risk of vascular disease (PROSPER): A randomised controlled trial. Lancet. 2002;360(9346):1623-30.

[13] Cholesterol Treatment Trialists' (CTT) Collaborators (2005) Efficacy and safety of cholesterol-lowering treatment: prospective metaanalysis of data from 90056 participants in 14 randomised trials of statins. Lancet 366: 12671278.

[14] Downs, J.R., Clearfield, M., Weis, S., Whitney, S., Shapiro, D.R. Beere, P.A. et al. (1998) Primary prevention of acute coronary events with lovastatin in men and women with average cholesterol levels: result of AFCAPS/TexCAPS. Air Force/Texas Coronary Atherosclerosis Prevention Study. JAMA 279: 16151622.

[15] Heart Protection Study Collaborative Group (2002) MRC/BHF Heart Protection Study of cholesterol lowering with simvastatin in 20536 high-risk individuals: a randomised placebo controlled trial. Lancet 360: 722. Heart Protection S.

[16] Sever, P.S., Dahlof, B., Poulter, N.R., Wedel, H., Beevers, G., Caulfield, M. et al. (2003) Prevention of coronary and stroke events with atorvastatin in hypertensive patients who have average or lowerthan-average cholesterol concentrations, in the AngloScandinavian Cardiac Outcomes Trial-Lipid Lowering Arm (ASCOT-LLA): multicentre randomized controlled trial. Lancet 361: 11491158.

[17] Neil, H.A., DeMicco, D.A., Luo, D., Betterridge, D.J., Colhoun, H.M., Durrington, P.N. et al. (2006) Analysis of efficacy and safety in patients aged 65-75 years at randomization: Collaborative Atorvastatin Diabetes Study (CARDS). Diabetes Care 29: 23782384

[18] Hawley, C., Roefaro, J., Forman, D., \& Orkaby, A. (2019). Statins for Primary Prevention in Those Aged 70 Years and Older: A Critical Review of Recent Cholesterol Guidelines. Drugs \& Aging, 36(8), 687 699. doi: 10.1007/s40266-019-00673-w.

[19] Aronow WS. Pharmacologic therapy of lipid disorders in the elderly. Am J Geriatr Cardiol. 2002;11(4):247-56.

[20] Cannon CP, Blazing MA, Giugliano RP, McCagg A, White JA, Theroux P, et al. Ezetimibe Added to Statin Therapy after Acute Coronary Syndromes. N Engl J Med. 2015;372(25):2387-97.

[21] Bohula EA, Morrow DA, Giugliano RP, Blazing MA, He P, Park JG, et al. Atherothrombotic Risk Stratification and Ezetimibe for Secondary Prevention. J Am Coll Cardiol. 2017;69(8):911-21.

[22] Bach RG, Cannon CP, Giugliano RP, White JA, Lokhnygina Y, Bohula EA, et al. Effect of Simvastatin-Ezetimibe Compared with Simvastatin Monotherapy after Acute Coronary Syndrome among Patients 75 Years or Older: A Secondary Analysis of a Randomized Clinical Trial. JAMA Cardiol. 2019;4(9):846-54.

[23] Sabatine MS, Giugliano RP, Keech AC, Honarpour N, Wiviott SD, Murphy SA, et al. Evolocumab and Clinical Outcomes in Patients with Cardiovascular Disease. N Engl J Med. 2017;376(18):1713-22.

[24] Hlatky MA, Kazi DS. PCSK9 Inhibitors: Economics and Policy. J Am Coll Cardiol [Internet]. 2017;70(21):2677-87. Available from: https://doi.org/10.1016/j.jacc.2017.10.001.

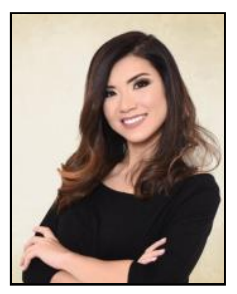

Micheli Ito Gimenes Pires was born in Umuarama-Paraná, Brazil in 1995 (January, 27th). Graduated from Unicesumar University with degree in Medicine, in Maringá-Paraná, Brazil, in 2nd semester of 2019. Major field of study is Internal Medicine.

She concluded undergraduate program in the field of Medicine and Health Sciences at Monash University, Melbourne-Austrália in 2016. Currently active in the program of medical residency in the field of Internal Medicine in Cajuru University Hospital, Curitiba-Paraná, Brazil. Main area of research interest is Internal Medicine. 


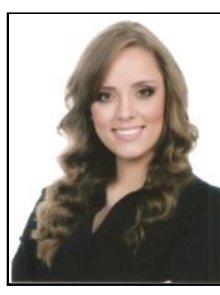

Thaise de Araujo Wrubleski was born in CuritibaParaná, Brazil in 1992 (August, 29th). Graduated from Pontifical Catholic University of Parana with degree in Medicine, in Curitiba-Paraná, Brazil, in 2nd semester of 2018. Major field of study is Internal Medicine.

She is currently active in the program of medical residency in the field of Internal Medicine in Cajuru University Hospital, Curitiba-Paraná, Brazil. Main area of research interest is Internal Medicine.

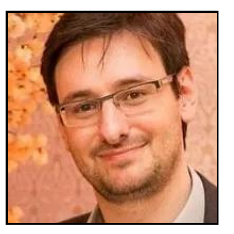

Gustavo Lenci Marques was born in União da Vitória,- Parana, Brazil in 1988 (February, 25 ${ }^{\text {th }}$ ). Graduated from Federal University of Parana with degree in Medicine, in Curitiba-Paraná, Brazil, in 2011. Major field of study is Internal Medicine and Cardiology.

He completed the program of medical residency in the field of Internal Medicine in 2014 and Cardiology in 2016, both in Federal University of Parana. Master's degree in Internal Medicine - 2015 and Ph. D. in Internal Medicine in 2020. Currently teaching and working at Cajuru University Hospital. Main area of research interest is Internal Medicine and Cardiology. 